\title{
La habitabilidad del espacio público en las ciudades de América Latina
}

\author{
Habitability of Public Space in Latin fmerican Cities \\ f habitabilidade do espaço público nas cidades da América Latina
}

\author{
Pablo Páramo* \\ Andrea Burbano* \\ Universidad Pedagógica Nacional, Bogotá, Colombia. \\ Bernardo Jiménez-Domínguez** \\ Verónica Barrios** \\ Universidad de Guadalajara, Guadalajara, México. \\ Carlota Pasquali*** \\ Universidad Simón Bolivar, Caracas, Venezuela. \\ Fabiola Vivas ${ }^{* * * *}$ \\ Oscar Moros ${ }^{* * * *}$ \\ Universidad Nacional Experimental del Táchira, San Cristóbal, Venezuela. \\ Mónica Alzate***** \\ Juan Carlos Jaramillo Fayad ${ }^{* * * * *}$ \\ Instituto Tecnológico Metropolitano, Medellín, Colombia. \\ Emilio Moyano****** \\ Universidad de Talca, Chile.
}

Doi: http://dx.doi.org/10.12804/revistas.urosario.edu.co/apl/a.4874

\footnotetext{
* Pablo Páramo, Doctorado Interinstitucional en Educación, Universidad Pedagógica Nacional, Bogotá, Colombia; Andrea Burbano, Departamento de Posgrados, Universidad Pedagógica Nacional, Bogotá, Colombia.

** Bernardo Jiménez-Domínguez, Verónica Barrios, Departamento de Estudios Sociourbanos, Universidad de Guadalajara, Guadalajara, México.

*** Carlota Pasquali, Departamento de Ciencia y Tecnología del Comportamiento Universidad Simón Bolívar, Caracas, Venezuela.

**** Fabiola Vivas, Departamento de Arquitectura, Universidad Nacional Experimental del Táchira, San Cristóbal, Venezuela; Oscar Moros, Departamento de Arquitectura, Universidad Nacional Experimental del Táchira, San Cristóbal, Venezuela.

***** Mónica Alzate, Juan Carlos Jaramillo Fayad, Instituto Tecnológico Metropolitano, Medellín, Colombia.

****** Emilio Moyano, Facultad de Psicología, Universidad de Talca, Chile.

La correspondencia relativa a este artículo debe ser enviada a Pablo Páramo, Ac 72 \#11-86, Bogotá, Colombia. Correo electrónico: pdeparamo@gmail.com
}

Cómo citar este artículo: Páramo, P., Burbano, A., Jiménez-Domínguez, B., Barrios, V., Pasquali, C., Vivas, F., Moros, O, Alzate, M., Jaramillo Fayad, J. C.\& Moyano, E. (2018). La habitabilidad del espacio público en las ciudades de América Latina. Avances en Psicología Latinoamericana, 36(2), 345-362. DOI: http://dx.doi.org/10.12804/revistas.urosario.edu.co/apl/a.4874 


\section{Resumen}

Este artículo presenta los resultados de un estudio descriptivo correlacional que investiga la evaluación personal de las condiciones que caracterizan la habitabilidad del espacio público en 11 ciudades de 7 países de América Latina: México, Colombia, Venezuela, Perú, Brasil, Chile y Argentina. En la investigación participaron un total de 1823 personas de ambos sexos y diferentes grupos de edad, que evaluaron la importancia y la satisfacción de diferentes características y condiciones del espacio público a través de un cuestionario ad hoc de 48 reactivos. Un análisis de escalamiento multidimensional de distancias mínimas (SSA) y de coordenadas de ordenamiento parcial (POSAC) indican que las personas evalúan las condiciones exploradas con base en la función que le atribuyen al espacio público de la ciudad. A pesar de las diferencias importantes entre las ciudades, hay coincidencias en varias condiciones del espacio público que, aunque se consideran importantes, no son reportadas como satisfactorias. Aparte de la importancia del conocimiento de la habitabilidad del espacio público en Latinoamérica, los resultados se discuten a partir de las consecuencias para la calidad de vida urbana y para la formulación de la política pública en la planificación y la gestión urbana.

Palabras clave: calidad de vida urbana, habitabilidad, espacio público, planificación urbana.

\section{fibstract}

This article presents the results of a descriptive correlational study that researches the personal assessment of the conditions that characterize the habitability of public space in eleven cities of seven Latin American countries: Mexico, Colombia, Venezuela, Peru, Brazil, Chile and Argentina. The research involved a total of 1823 people of both sexes and various age groups who assessed the importance and satisfaction of different characteristics and conditions of public space through an ad hoc questionnaire of 48 items. A multidimensional scaling analysis of smallest space (SSA) and partial or- dering scalogram (POSAC) indicate that people evaluate the conditions explored based on the function that they attribute to the city's public space. Despite the important differences among cities, there are coincidences on several characteristics of public space that, although considered important, are not reported as satisfactory. Aside the value of understanding the habitability of public space in Latin America, the results are discussed from the perspective of the implications for urban quality of life and for the formulation of public policy on urban planning and management.

Keywords: quality of urban life, habitability, public space, urban planning.

\section{Resumo}

Este artigo apresenta os resultados de um estudo descritivo de correlação que investiga a avaliação pessoal das condições que caracterizam à habitabilidade do espaço público em onze cidades de sete países da América Latina, o México, a Colômbia, a Venezuela, o Peru, o Brasil, o Chile e a Argentina. Na pesquisa participaram um total de 1823 pessoas de ambos os sexos e diferentes grupos de idade, que avaliaram a importância e a satisfação de diferentes características e condições do espaço público através de um questionário ad hoc de 48 reativos. Uma análise de escalamento multidimensional de distâncias mínimas (SSA) e de coordenadas de ordenamento parcial (POSAC) indicam que as pessoas avaliam as condições exploradas com base na função que lhe atribuem ao espaço público da cidade. A pesar das diferenças importantes entre as idades, há coincidências em várias condições do espaço público que, ainda que consideram importantes, não são reportadas como satisfatórias. Aparte da importância do conhecimento da habitabilidade do espaço público na Latino-América, os resultados se discutem a partir das consequências para a qualidade de vida urbana e para a formulação da política pública na planificação e gestão urbana.

Palavras-chave: qualidade de vida urbana, habitabilidade, espaço público, planificação urbana. 


\section{Introducción}

Si bien los estudios iniciales en la psicología enfatizaban en la habitabilidad como una condición de la vivienda (Mercado, 1995), el desarrollo posterior de esta noción fue extendiéndose a su medio externo. Así, Mercado, Ortega, Estrada y Luna (1995), y Landázuri y Mercado (2004) conciben la habitabilidad desde dos perspectivas: en el interior de la vivienda y la externa, la cual se refiere al siguiente nivel sistémico dentro del modelo ecológico de Bronfenbrenner (1971), es decir, el vecindario donde se ubica la vivienda y los equipamientos urbanos: escuelas, hospitales, medios de transporte, parques y avenidas, y la manera como los usuarios hacen uso de estos espacios. En una dirección similar lo analizan Marquina y Pasquali (2006), desde la perspectiva de las necesidades humanas establecidas por Max-Neef, Elizalde y Hopenhayn (1986), en su visión acerca de los espacios públicos como medios satisfactores de necesidades humanas.

Buena parte de las condiciones de la vivienda y la infraestructura de la ciudad es evaluada mediante diferentes indicadores en el contexto de los estudios psicológicos sobre calidad de vida urbana, pero son pocos los que se concentran sobre el espacio público en las ciudades latinoamericanas, aunque con algunas excepciones (Alcalá, 2007; Marquina \& Pasquali, 2006; Páramo \& Burbano, 2013). Tal vez este desinterés se deba, como afirman Valladares, Chávez y López (2015), a que el espacio público urbano no se ha considerado un lugar que pueda ser habitado, sino de "tránsito", donde la habitabilidad no tiene lugar.

Dada la carencia de estudios en los países de la región, el presente trabajo se propuso evaluar las condiciones que hacen habitable el espacio público en una muestra internacional de diferentes ciudades latinoamericanas. Se parte de considerar el espacio público un aspecto clave que debe ser tenido en cuenta al evaluar la calidad de vida de las ciudades latinoamericanas, por tratarse de los lugares por excelencia donde todavía interactúan los habitantes de la ciudad. El espacio público no existe si no es en relación con la ciudad operando como un sistema, o porque el conjunto de la ciudad la entiende como tal. La ciudad es un espacio público a partir del cual se organiza la vida colectiva y donde hay una representación de esa sociedad. De allí surge la necesidad de entenderlo como uno de los derechos fundamentales de la ciudadanía frente a la ciudad: el derecho al espacio público, a la asociación, a la identidad y a la polis (Borja \& Muxi, 2000; Delgado, 2011).

Partimos de considerar el espacio público un componente esencial del bienestar de las personas en las ciudades y, por tanto, de la importancia de su visibilidad en la evaluación de los aspectos que propician la calidad de vida del ser humano en los distintos ámbitos que forman parte de su experiencia en la urbe. El espacio público, como lugar donde se gestan prácticas sociales que contribuyen al encuentro de las personas, debe ser habitable y, por tanto, impactar en la calidad de vida urbana. Un espacio se considera habitable en tanto satisface necesidades humanas. Quienes ocupan dichos lugares de manera permanente o transitoria en torno a prácticas como la socialización, la protesta ciudadana, la lúdica y el entretenimiento, las expresiones asociadas con el género, el comercio y demás expresiones culturales necesitan imaginarse condiciones espaciales, de equidad, seguridad y confort, que les permitan hacer uso de los espacios públicos, permanecer, sentirse cómodos, identificarse y apropiarse de ellos (García-Canclini, 2005; Silva, 1992; Vergara, 2003).

A pesar de su importancia para evaluar la calidad de vida urbana, el espacio público generalmente no se encuentra incluido como indicador directo, ni está asociado como indicador marginal, ${ }^{1}$

Dentro de los indicadores más usados están: necesidades básicas insatisfechas (indicadores sobre escolaridad, dependencia económica, hacinamiento, vivienda y materiales de vivienda, servicios públicos domiciliarios, pobreza y miseria), las líneas de pobreza e indigencia (medición por 
por lo que se propone vincularlo como indicador de la calidad de vida urbana, considerando las evaluaciones objetivas de infraestructura urbana, que ya existen, como equipamientos deportivos y culturales, servicios urbanos (baños públicos, parqueaderos para bicicletas, fuentes de agua), calidad del ambiente (espacios verdes, parques por habitante, calidad del aire) y su accesibilidad en términos de transporte; y subjetivas, que proponemos desarrollar a partir de la percepción de los ciudadanos acerca de la función que cumplen esos mismos elementos para: la recreación, la integración social, la protección del clima, las celebraciones culturales, la comunicación, la expresión social (protestas), la seguridad (confianza en la policía, iluminación de parques, calles y plazas), la articulación entre los distintos componentes del espacio público, la equidad, la integración social que favorece accesibilidad, la calidad de los servicios (aseo, baños públicos, parqueaderos) y la estética de las construcciones y del paisaje. Además, están las más disímiles prácticas urbanasculturales a las que se refiere Licona (2007), lo que hace permisible la convivencia tanto entre los vecinos, como entre los vendedores y trabajadores que lo habitan (García, 2014).

La valoración del espacio público, desde la mencionada perspectiva, daría cuenta de la habitabilidad que presenta, lo cual se constituye en una condición adicional de la calidad de vida urbana, entendida como las condiciones que hacen a un ambiente habitable en términos de confort, lo cual se asocia a lo ecológico, biológico, económicoproductivo, sociocultural, tipológico, tecnológico y estético en sus dimensiones espaciales y psicosociales dentro del espacio donde el hombre habita y actúa. Estas en el ámbito de la ciudad están íntimamente vinculadas a un determinado grado de satisfacción de unos servicios y a la percepción del

ingresos), y el Gini (coeficiente que se utiliza sobre todo para medir la desigualdad en los ingresos). En ninguno de estos se establece el espacio público como indicador. espacio habitable: los parques, zonas verdes, la recreación y los aspectos de calidad físico-ambiental (Leva, 2005). Además, dentro de esta noción se incluyen aspectos como la satisfacción respecto a la vida en general; la vida social; las relaciones interpersonales; la vida familiar, escolar y laboral; la expresión emocional; la seguridad y la productividad personal; y como valoración objetiva, al considerar el bienestar material, el acceso a empleo, el ambiente físico, la seguridad, los medios de transporte, la igualdad económica, entre otros (Ardila, 2003; Moreno, 2008), mostrándose de este modo como un concepto multidimensional (Moyano, Núñez \& Jiménez, 2010). Es en este marco multidimensional que el espacio público desde su habitabilidad se constituye en uno de los satisfactores de la calidad de vida urbana.

Una ciudad es valorada como buena o mala dependiendo asimismo de las experiencias que los individuos tengan en relación con "otros". El hecho de hacer parte de redes sociales es un elemento importante de la identidad del individuo con un territorio, contribuye a prevenir el aislamiento social y, por consiguiente, mejora la percepción de la vida en la ciudad. Es por esto que la dimensión espacial de la ciudad se constituye en un facilitador de la socialización entre las personas. Para Carrión (2004), la ciudad es el espacio que concentra la heterogeneidad social de un grupo poblacional grande y denso, que requiere de espacios de encuentro que permitan la unidad dentro de la diversidad y, de esta manera, ayudar a definir la ciudadanía. Contar con amigos, vecinos $y$ tener un sentido de pertenencia a una comunidad, sentirse parte de la ciudad y ser reconocido como parte de ella constituyen elementos importantes para hacer su valoración en términos de la calidad de vida percibida. El mobiliario urbano, la existencia de los parques, las plazas, las aceras, los lugares de encuentro, los pianos en las calles, la vegetación son algunos de los elementos que actúan como oportunidades para los encuentros 
sociales que contribuyen a la creación del tejido social (Páramo, 2007; Burbano, 2014).

Sin embargo, en las ciudades latinoamericanas, al seguir el modelo urbanístico estadounidense en años recientes (Oldemburg, 2011; Jiménez-Domínguez, 2007; García, 2014) y como consecuencia de la globalización, se ha venido perdiendo la vitalidad urbana y disminuyéndose la satisfacción de los residentes de las ciudades. Se han debilitado los lugares para el encuentro social para hablar, discutir y, en general, disfrutar de la compañía de otros, al remplazarse los espacios públicos por centros comerciales y grandes supermercados que han venido destruyendo la dinámica social; han creado una dualidad que consiste, según Jiménez-Domínguez (2007), de una red de espacios globalizados, privatizados y homogenizados, por una parte, $y$, por otra, una ciudad que es cada día más invisible, poseedora de una economía informal urbana, además de una intensa polarización del espacio, al igual que de una gran variedad e impredictibilidad, lo que conduce a una sociedad polarizada que segrega los usos de los espacios urbanos. En este sentido, los que no logran adaptarse a la aldea global generan desarraigo, desestabilización y crisis (García, 2014). Este tipo de dinámicas urbanas descontroladas ha cercenado, según Vivas (2006), una de las condiciones para que un espacio urbano se transforme en un verdadero espacio público: facilitar la interacción social entre sus ciudadanos y lograr su identificación con dichos espacios. Las representaciones que circulan sobre los espacios públicos de las ciudades latinoamericanas son de calles deterioradas, inseguras, congestionadas por las ventas ambulantes y contaminadas en niveles críticos, es decir, sin capacidad para ofrecer atractivo alguno de vida urbana, pero con pocas mediciones al respecto.

La comparación mediante indicadores para evaluar la calidad de vida de las ciudades tiene implicaciones en la toma de decisiones para el turismo, la elección del lugar donde vivir o donde abrir oficinas por parte de las compañías. La revista Monocle, en su listado anual señala que Tokio, Viena, Berlín, Melbourne y Sídney ocupaban los primeros cinco lugares como ciudades más vivibles, después de tener en cuenta criterios como el nivel de ingresos; la calidad y la disponibilidad del empleo; la disparidad entre clases sociales; la tasa de pobreza; la calidad y la accesibilidad a la vivienda; la tasa de inflación; la incidencia de enfermedades; el costo de servicios públicos; la estabilidad política; los estándares educativos; la seguridad; la conectividad internacional; el clima; la calidad de la arquitectura; el transporte público; la tolerancia; las condiciones ambientales; el acceso a la naturaleza; el diseño urbano; las condiciones económicas; la política proactiva; y la atención médica. En este mismo sentido, se encuentra el informe Mercer (2015), que compara las ciudades a partir de 39 criterios o indicadores similares a los de Monocle, entre los que se incluyen las condiciones económicas, ambientales, de salud, políticas, etc. Según este informe, las cinco ciudades mejor evaluadas para el 2015 fueron: Viena, Zúrich, Auckland, Múnich y Vancouver. Por su parte, el Data Team (2015) considera 30 factores entre los que incluyen la seguridad, el acceso a la salud, los recursos educativos, la infraestructura y el ambiente, entre otros. Se encuentran en esta medición las ciudades de Melbourne, Viena, Vancouver, Toronto y Calgary dentro de los primeros cinco lugares.

Es de anotar que en estos listados ninguna ciudad latinoamericana figura dentro de los primeros 50 puestos. En la revista Monocle ("Monocle's quality of life survey", 2015), en Suramérica Montevideo se ubica en el puesto 78, Buenos Aires en el 91 y Santiago en el 93, mientras que La Paz se ubica en el puesto 156 y Caracas en el 179. Entre los aspectos considerados en el análisis para el caso particular de las ciudades latinoamericanas que no contribuyen a su calidad de vida, se señalan la inestabilidad política, la desigualdad en los 
ingresos, la incertidumbre económica, el narcotráfico en México y Colombia, lo mismo que el crimen callejero y el miedo al secuestro. Existen igualmente mediciones en América Latina para evaluar la calidad de vida, como es el caso de México (Gabinete de Comunicación Estratégica, 2013) o para evaluar la gestión de gobierno de una alcaldía, como sucede en Colombia mediante la medición Red Colombiana de Ciudades Cómo Vamos (2014), pero en las que se les presta poca atención a las condiciones propias de la experiencia urbana en los espacios públicos.

A partir de la importancia que reviste incluir la habitabilidad del espacio público como un satisfactor de la calidad de vida, se considera necesario indagar y comparar la percepción que las personas tienen de la calidad de los espacios públicos de las ciudades latinoamericanas desde la valoración de algunas condiciones que los hacen habitables a partir de un instrumento creado para tal fin.

\section{Método}

El estudio es descriptivo de tipo correlacional, comparando 11 matrices de datos correspondientes a las ciudades de los países participantes.

\section{Participantes}

En el estudio participaron voluntariamente 1823 personas pertenecientes a 7 países latinoamericanos y 11 ciudades: Bogotá, Buenos Aires, Caracas, Fortaleza, Guadalajara, Lima, Medellín, Puebla, San Cristóbal, Sao Paulo (Jundiaí) y Talca, con las cuales se logró conformar el equipo de investigación. Se utilizó un muestreo de tipo no probabilístico intencional. La muestra fue estratificada según cuatro rangos de edad, desde 18 a 75 años. Un 50,3\% de los participantes son mujeres ( $\mathrm{n}=917)$, un $49,15 \%$ son hombres $(\mathrm{n}=896)$, un $0,16 \%(\mathrm{n}=3)$ informó pertenecer a otro género $\mathrm{y}$ el $0,39 \%(n=7)$ no respondió la pregunta (tabla 1$)$.
En la tabla 1 se presenta la distribución de la muestra según la cantidad de cuestionarios aplicados en las ciudades y la distribución de participantes según el rango de edad.

\section{Instrumento}

Se construyó un instrumento ad hoc compuesto por 48 reactivos con diversas condiciones que se observan en el espacio público de las ciudades, 47 de los cuales fueron valorados a partir de dos escalas: el grado de importancia, con una escala de siete puntos, desde muy poco importante (1) a muy importante (7), y el nivel desatisfacción con una escala que iba de -3 , muy insatisfecho, pasando por el valor 0 , indiferente, hasta +3 , muy satisfecho. Una última escala monoítem interrogó por la valoración general que la persona hace del espacio público de la ciudad que habita, en la que 1 corresponde a muy poco habitable, 2 poco habitable, 3 medianamente habitable, 4 habitable y 5 muy habitable. Se incluyó la opción de respuesta "no sabe" para los casos en los que la situación a evaluar no aplica, según el punto de vista del participante. Los reactivos resultaron de la revisión de la literatura sobre las condiciones que hacen habitable el espacio público, que, a su vez, dieron lugar al instrumento construido por Páramo \& Burbano (2013) complementado por el equipo de investigadores internacional. Al final del instrumento se incluyeron preguntas sobre las características sociodemográficas del participante, como la edad, el género y el barrio en que vive. El instrumento se aplicó de manera asistida por estudiantes a una muestra por conveniencia en cada ciudad. En todos los casos la participación fue anónima y voluntaria. El cuestionario fue ajustado en sus ítems y expresiones por el grupo de investigación de cada ciudad hasta lograr acuerdos entre los grupos sobre el sentido de los ítems. Igualmente, el instrumento fue validado por tres jueces independientes y mediante estudio piloto llevado a cabo en Colombia con 60 participantes. 
Tabla 1

Distribución de la muestra por ciudades según edad y género

\begin{tabular}{|c|c|c|c|c|c|c|c|c|c|c|}
\hline \multirow[b]{2}{*}{ Ciudad } & \multicolumn{5}{|c|}{ Edad } & \multicolumn{4}{|c|}{ Género } & \multirow[b]{2}{*}{ Total } \\
\hline & $\begin{array}{l}18-30 \\
\text { años }\end{array}$ & $\begin{array}{l}31-45 \\
\text { años }\end{array}$ & $\begin{array}{l}46-60 \\
\text { años }\end{array}$ & $\begin{array}{l}61 \text { años en } \\
\text { adelante }\end{array}$ & N/A & Femenino & Masculino & Otro & N/A & \\
\hline Bogotá & 109 & 74 & 30 & 5 & 3 & 102 & 114 & 1 & 4 & 221 \\
\hline Buenos Aires & 35 & 37 & 9 & 0 & 0 & 41 & 40 & 0 & 0 & 81 \\
\hline Caracas & 81 & 70 & 32 & 14 & 0 & 97 & 99 & 1 & 0 & 197 \\
\hline Fortaleza & 114 & 37 & 24 & 4 & 0 & 102 & 77 & 0 & 0 & 179 \\
\hline Guadalajara & 95 & 24 & 30 & 13 & 0 & 94 & 67 & 1 & 0 & 162 \\
\hline Lima & 82 & 46 & 15 & 8 & 0 & 78 & 73 & 0 & 0 & 151 \\
\hline Medellín & 176 & 39 & 10 & 2 & 1 & 123 & 104 & 0 & 1 & 228 \\
\hline Puebla & 96 & 18 & 21 & 10 & 4 & 70 & 79 & 0 & 0 & 149 \\
\hline San Cristóbal & 86 & 55 & 42 & 17 & 0 & 114 & 86 & 0 & 0 & 200 \\
\hline Sao Paulo (Jundiaí) & 40 & 55 & 17 & 2 & 3 & 27 & 88 & 0 & 2 & 117 \\
\hline Talca & 110 & 12 & 13 & 3 & 0 & 69 & 69 & 0 & 0 & 138 \\
\hline Total & 1028 & 467 & 243 & 78 & 11 & 917 & 896 & 3 & 7 & 1823 \\
\hline Porcentaje & 56,3 & 25,6 & 13,3 & 4,2 & 0,6 & 50,3 & 49,1 & 0,16 & 0,39 & 100 \\
\hline
\end{tabular}

En Brasil fue traducido al portugués y vuelto a traducir al castellano para asegurar el mismo sentido de los ítems. Para el análisis de la consistencia interna del instrumento, se utilizó la prueba Alfa de Cronbach cuyo índice varió, al ser aplicado en las ciudades, entre 0,938 a 0,949 , lo que indica que el instrumento posee una adecuada confiabilidad.

\section{Procedimiento}

Se aplicó el cuestionario bajo la dirección de los equipos de investigación y un consentimiento informado se obtuvo de los participantes de cada país asegurándoles que la información recogida sería completamente anónima. Los datos fueron recolectados durante mayo y julio del 2015.

\section{Resultados y discusión}

Con el fin de comparar las valoraciones de los participantes sobre la habitabilidad del espacio público en términos de las distintas condiciones, se compararon los valores de las medias para cada ítem de todas las ciudades (figura 1). En términos generales, se observa que las condiciones evaluadas en la escala de importancia ( 1 a 7 ) fueron valoradas como de importancia entre media y alta. Se destacan con valores altos (promedio 6,30 sobre 7) los ítems 20 y 23 , que están relacionados con la presencia de elementos naturales, el aseo y la limpieza en las calles, lo que concuerda con los resultados de Marquina y Pasquali (2006), ya que son dos de los elementos más importantes al evaluar niveles de satisfacción, mientras que el ítem 4 obtuvo el promedio más bajo de 3,65 , el cual está referido a la presencia de manifestaciones religiosas en la calle.

Por otro lado, en lo que corresponde al grado de satisfacción, evaluado a partir de una escala discreta comprendida ente -3 (muy insatisfecho) y 3 (muy satisfecho), donde 0 indica indiferencia (panel B de la figura 1), solo 4 ítems señalan niveles 
altos de satisfacción y seis con algo de satisfacción. Aparte de los dos ítems de indiferencia, todos los demás señalan insatisfacción. Los encuestados se mostraron medianamente satisfechos con la ausencia de personas viviendo en la calle (ítem $7, \bar{x}=1,2$ ), puntuación más alta en promedio; en contraste, se encuentran insatisfechos con el nivel de ruido en las calles (ítem $34, \bar{x}=1,4$ ). No obstante, los resultados indican que, en general, a las personas les resulta indiferente la presencia de manifestaciones religiosas (ítem 4), artísticas (ítem 6), la accesibilidad desde el lugar de vivienda (ítem 15) y que se cuente con espacios para practicar deportes (ítem 21).

Estos resultados señalan que los ciudadanos reconocen que los elementos que componen el espacio público son relevantes para el disfrute de la vida en público, por lo que todos son "bien" valorados respecto a su importancia, aunque se muestren insatisfechos con el estado en que se encuentran. Sienten que dichos espacios no cumplen con su función, lo cual tiene implicaciones serias para la calidad de vida, afectando componentes primordiales de las necesidades humanas básicas.

\section{PANEL A IMPORTANCIA}

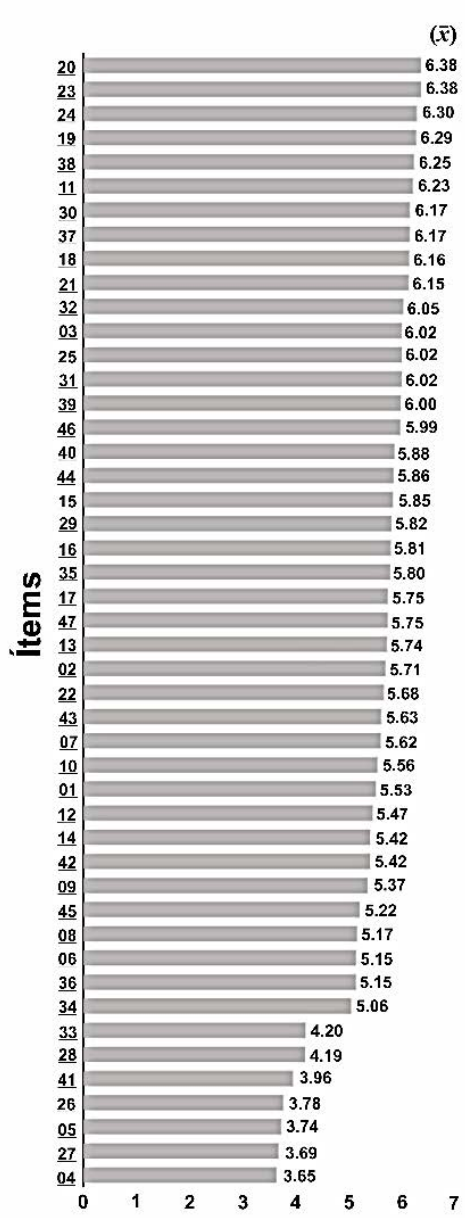

PANEL B SATISFACCIÓN

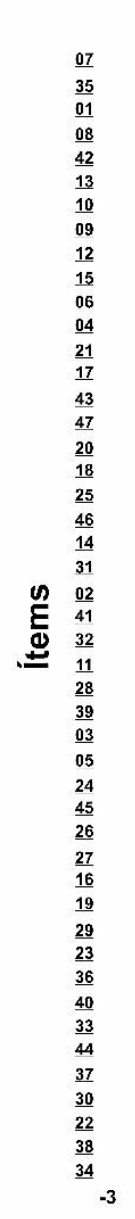

\begin{tabular}{|c|c|}
\hline Item & Item \\
\hline 1. Clima & 25. Seת̃alización \\
\hline 2. Elementos físicos & 26. Grafitis en muros \\
\hline 3. Calidad aire & 27. Publicidad auditiva \\
\hline 4. Manifestaciones religiosas & 28. Publicidad visual \\
\hline 5. Manifestaciones políticas & 29. Presen cámaras seguridad \\
\hline 6. Manifestaciones artisticas & 30. Presen. pelicíápersonal seguridad \\
\hline $\begin{array}{l}\text { 7. Auscne, personas vivicndo } \\
\text { en la calle }\end{array}$ & 31. Esp. recreación niños \\
\hline $\begin{array}{l}\text { 8. Auscneia trabajadorcs } \\
\text { sexuales }\end{array}$ & 32. Esp. recreación jóvenes \\
\hline 9. Diversidad obs. y exp & $\begin{array}{l}\text { 33. Comercio/ventas informales } \\
\text { callejeras }\end{array}$ \\
\hline 10. Variedad esp. públicos & 34. Nivel ruido calles \\
\hline 11. Movilidad peatón & 35. Ausenc, malos olores \\
\hline 12. Hitos culturales & 36. Humo fumadores \\
\hline 13. $\Lambda$ ctiv culturales gratuitas & 37. Respeto a reglas convivencia \\
\hline 14. Estética fachadas & 38. Respeto normas tránsito \\
\hline $\begin{array}{l}\text { 15. Accesibilidad desde } \\
\text { vivienda }\end{array}$ & 39. Tequitativo esp. público \\
\hline $\begin{array}{l}\text { 16. Infracsituctura mov. } \\
\text { biciclecta }\end{array}$ & 40. Estado mallit o red vial \\
\hline $\begin{array}{l}\text { 17. Mov. bicicletas } \\
\text { domingos festivos }\end{array}$ & 41. Presenc, artistas cruces calles \\
\hline 18. Mobiliario csp. público & 42. Txistencia cajecros autśmaticos \\
\hline $\begin{array}{l}\text { 19. Rampas para } \\
\text { desplazamiento }\end{array}$ & 43. Concectividad entre esp. públicos \\
\hline 20. Elementos naturales & 44. Nivel participación ciudadana \\
\hline 21. Esp públicos para deportc & 45. Presenc. tecnología \\
\hline 22. Existencia baños públicos & $\begin{array}{l}\text { 46. Cond. esp. público ejercicio } \\
\text { reducción estrés }\end{array}$ \\
\hline 23. Aseo calles & 47. Dispo. escenarios públ. para \\
\hline 24. Tluminación nocturna & \\
\hline
\end{tabular}

Figura 1. Promedio de los ítems en la escala de importancia (panel A) y satisfacción (panel B) 


\section{Análisis de la información mediante el escalamiento multidimensional}

Con el propósito de explorar la manera en que los participantes estructuran conceptualmente su valoración de las condiciones asociadas con la habitabilidad del espacio público, las respuestas a los distintos ítems fueron examinadas mediante un análisis de distancias mínimas (Smallest Space Analysis [SSA]) (Borg \& Groenen, 2005), a través del programa Hudap ${ }^{\circledR}$. El SSA correlaciona los ítems siguiendo las especificaciones de la correlación Pearson. ${ }^{2}$ Las correlaciones espaciales que arrojó el programa permitieron señalar regiones significativas en los respectivos planos para cada una de las escalas.

\section{Importancia}

La figura 2 muestra la distribución espacial de las correlaciones de la escala "importancia”. Según la distribución de la correlación de los ítems, se puede observar que estos se organizan a partir del grado de importancia que los participantes otorgan a las situaciones que evalúa el cuestionario; en la parte izquierda del plano se encuentran los ítems con menor media o menos valorados, y en la derecha se ubican los de mayor media o valorados como más importantes. Al revisar esta distribución y el contenido de los ítems, se crearon tres regiones a las que se les denominó de izquierda a derecha: expresión cultural y comercio, calidad del aire, y diseño y funcionalidad urbana. La región de expresión cultural agrupa aspectos como la

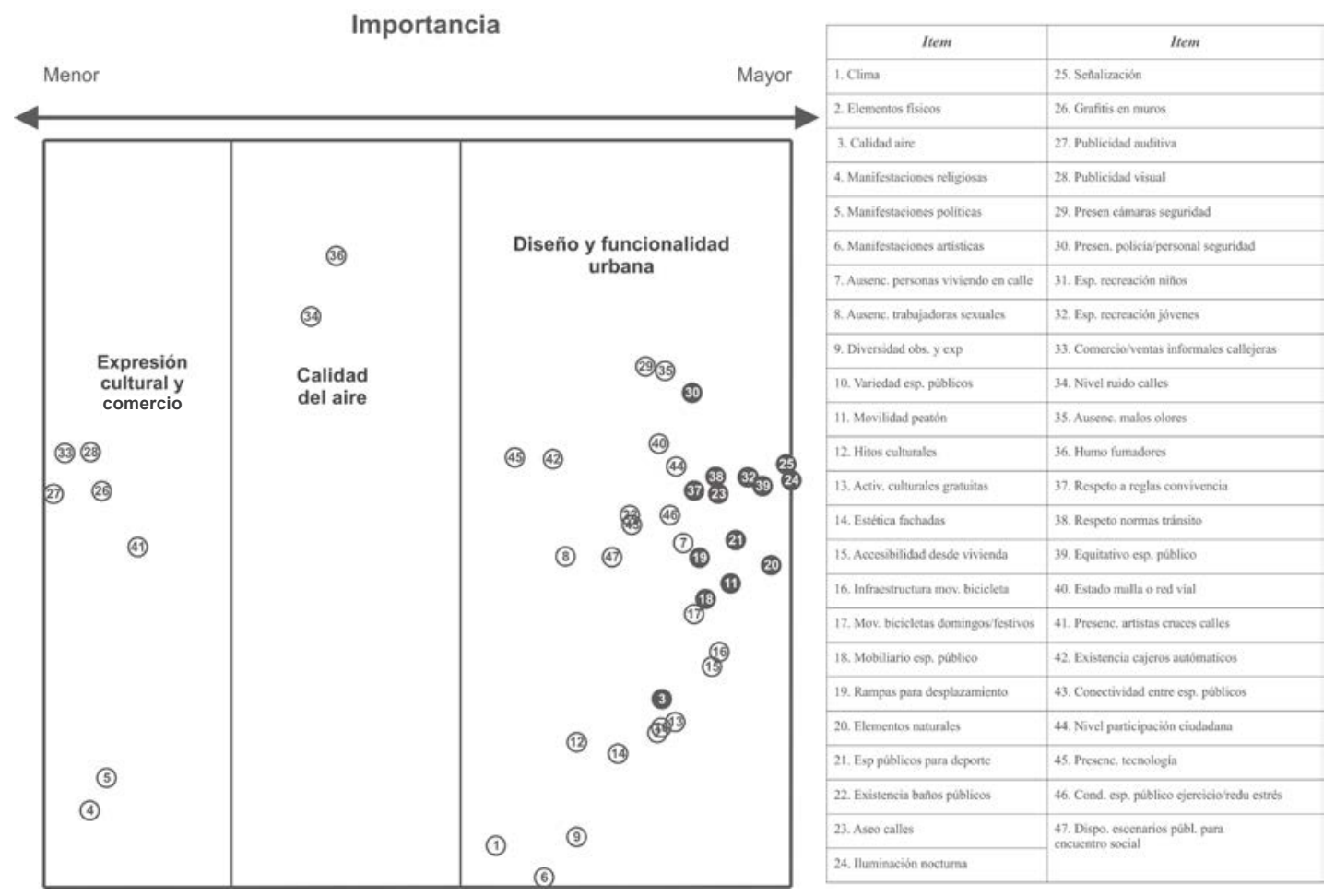

Figura 2. Diagrama de análisis de distancias mínimas espaciales SSA de la escala "importancia"

2 Los resultados de la correlación Pearson se muestran dentro de un plano que permite observar los ítems como puntos geométricos, de tal forma que entre más similares en términos de la correlación entre ellos, más cerca se encontrarán espacialmente. Para llevar a cabo este análisis se crearon matrices independientes para las escalas de importancia y satisfacción del cuestionario. 
presencia de artistas en los cruces de calles y grafitis en los muros, y aspectos de la dinámica comercial de las ciudades, como son tanto la publicidad visual y auditiva en las calles como las ventas informales. En la región de calidad del aire se encuentran las condiciones de nivel de ruido en las calles y el humo de fumadores en los espacios públicos. La región de diseño y funcionalidad urbana, la cual incluye la mayor parte de ítems del cuestionario, agrupa aspectos como la presencia de elementos físicos para protegerse de cambios climáticos; la armonía en las fachadas de las edificaciones; mobiliario en el espacio público (bancas, teléfonos públicos y recipientes para la basura, entre otros); elementos naturales y espacios públicos para practicar deporte; presencia de hitos culturales (esculturas, monumentos y obras de arte, entre otros); aspectos que hacen posible la funcionalidad de la ciudad y que están relacionados con el estado de la malla vial y aquellas condiciones que facilitan la movilidad de peatones (calles peatonalizadas, andenes, rampas y bicicletas); elementos de seguridad consistentes en la presencia de personal y cámaras de seguridad; $\mathrm{y}$, finalmente, condiciones de tecnología asociadas a la presencia de pantallas gigantes en el espacio público y disponibilidad de cajeros automáticos.

\section{Satisfacción}

Al interpretar el plano que arrojó el programa SSA, se diagramaron ocho grupos o regiones (figura 3). La primera, denominada estructura y dinámica urbana, reúne las características de accesibilidad, disponibilidad de espacios para movilizarse en bicicleta, movilidad para peatones, conectividad entre

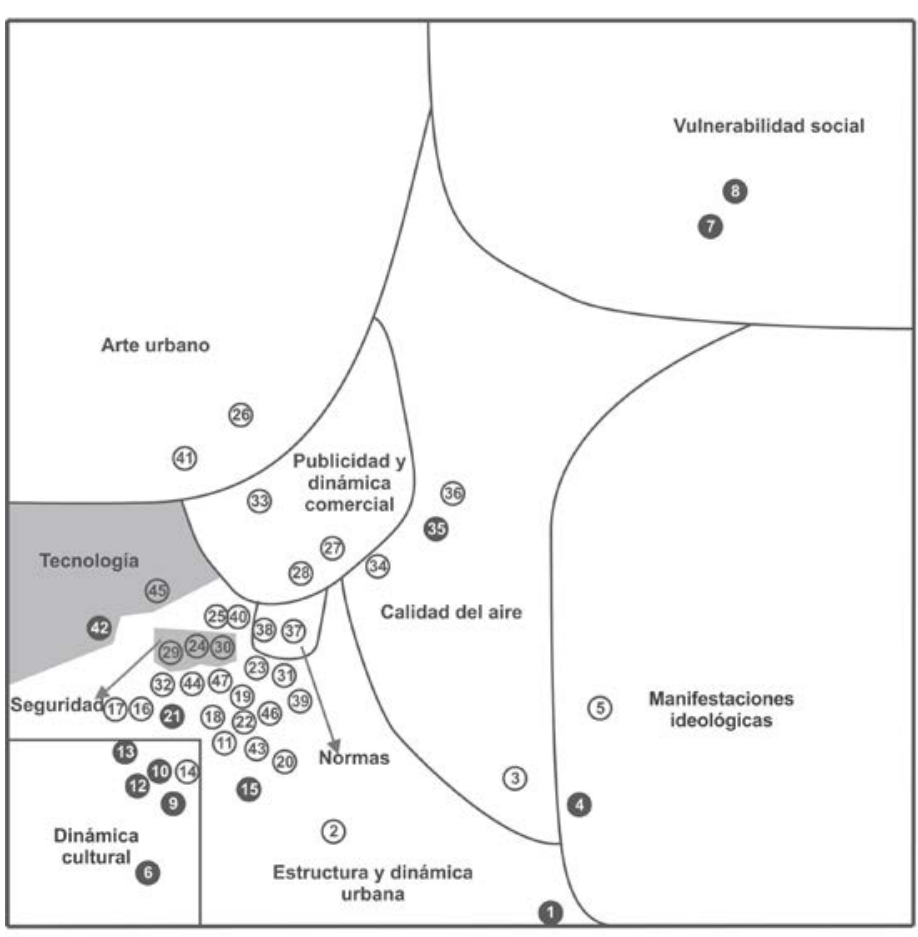

\begin{tabular}{|c|c|}
\hline Hem & Item \\
\hline 1. Clima & 25. Senalización \\
\hline 2. Elementos físicos & 26. Grafitis en muros \\
\hline 3. Calidad aire & 27. Publicidad auditiva \\
\hline 4. Manifestaciones religiosas & 28. Publicidad visual \\
\hline 5. Manifestaciones politicas & 29. Presen cámaras seguridad \\
\hline 6. Manifestaciones artisticas & 30. Presen, policiajpersonal seguridad \\
\hline 7. Ausenc, personas viviendo en calle & 31. Esp, recreación nithos \\
\hline 8. Ausenc. trabajadoras sexuales & 32. Esp, recreación jóvenes \\
\hline 9. Diversidad obs. y exp & 33. Comercio'ventas informales callejeras \\
\hline 10. Varicdad esp, püblicos & 34. Nivel ruido calles \\
\hline 11. Movilidad peatón & 35. Ausenc. malos olores \\
\hline 12. Hitos culturales & 36. Humo fumadores \\
\hline 13. Activ, culturales gratuitas & 37. Respeto a reglas convivencia \\
\hline 14. Estética fachiadas & 38. Respeto normas trainsito \\
\hline 15. Accesibilidad desde vivienda & 39. Equitativo esp. público \\
\hline 16. Infraestructura mov bicicleta & 40. Estado malla o red vial \\
\hline 17. Mov. bicicletas domingos festivos & 41. Presenc, artistas eruces calles \\
\hline 18. Mobiliario esp. püblico & 42. Existencia cajecros autómaticos \\
\hline 19. Rampas para desplazamiento & 43. Conectividad entre esp. públicos \\
\hline 20. Elementos naturales & 44. Nivel participación ciudadana \\
\hline 21. Espp públicos para deporte & 45. Presenc. teenologia \\
\hline 22. Existencia banos públicos & 46. Cond. esp. público ejercicio redu estrís \\
\hline 23. Aseo calles & $\begin{array}{l}\text { 47. Dispo. escenarios pübl. para } \\
\text { encuentro social }\end{array}$ \\
\hline Iminación no & \\
\hline
\end{tabular}

Figura 3. Diagrama de análisis de distancias mínimas espaciales SSA de la escala "satisfacción" 
los espacios públicos, lugares para hacer ejercicio, aseo en las calles y señalización; adicionalmente, incluye infraestructura como baños públicos, malla vial, andenes, rampas, iluminación nocturna, mobiliario urbano, escenarios públicos y elementos naturales. En esta región se localizan dos subregiones, que han sido denominadas tecnología, que agrupa la presencia de pantallas gigantes y cajeros automáticos, y seguridad, que comprende la presencia tanto de cámaras de seguridad como de policías y personal de seguridad en el espacio público. La segunda área del plano, llamada publicidad y dinámica comercial, reúne las condiciones de publicidad auditiva y visual en las calles y ventas informales callejeras, mientras que la tercera región ha sido referenciada como arte urbano en razón a la presencia de artistas en los cruces de calles y de la expresión a través de los grafitis en los muros de la ciudad. La región denominada dinámica cultural reúne condiciones relacionadas con manifestaciones artísticas en la calle e hitos culturales como monumentos y esculturas, entre otros, y la realización de actividades culturales gratuitas como desfiles, conciertos, etcétera. La quinta área, llamada manifestaciones ideológicas, abarca las expresiones religiosas y políticas en el espacio público. La región definida como calidad del aire agrupa condiciones de ausencia de malos olores en el espacio público, nivel de ruido en las calles y la percepción de la calidad del aire. La séptima área, a la que hemos denominado normas, reúne condiciones que tienen que ver con el respeto de las reglas de convivencia y las normas de tránsito. Finalmente, la región de vulnerabilidad social hace alusión a la presencia de trabajadoras sexuales y personas viviendo en las calles. Es importante notar que los ítems resaltados en oscuro, que son los que se encuentran en los grados más altos de

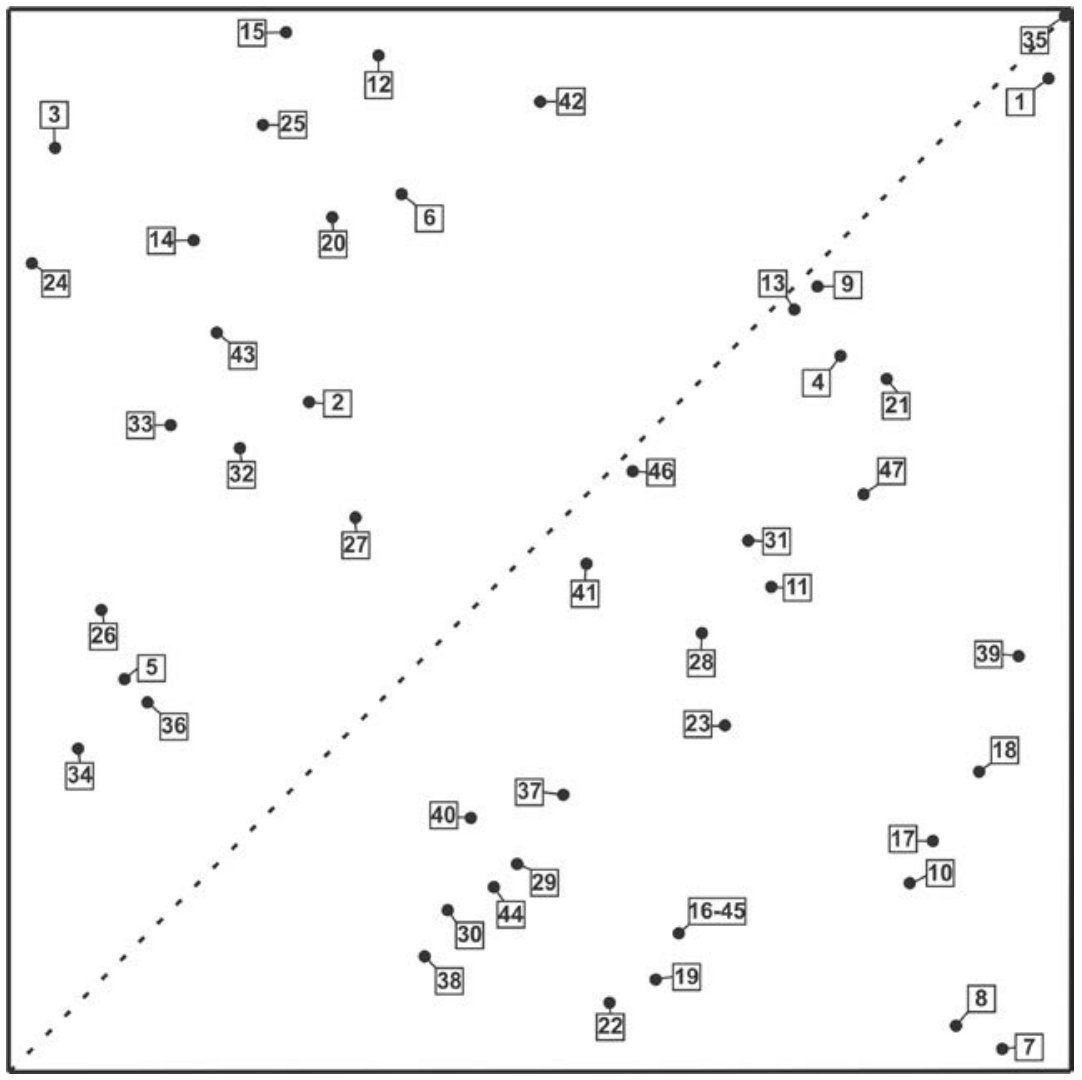

Figura 4. Análisis principal Posac según la ciudad 
satisfacción (figura 3) se encuentran parcialmente dispersos. Corresponden a agrupaciones diversas y, en algunos casos, en categorías alejadas del núcleo principal, donde se agrupan la mayoría de ítems que, a su vez, arrojan bajos niveles de satisfacción.

\section{Análisis de la información entre ciudades mediante el escalamiento multidimensional de orden parcial (POSAC)}

Para analizar las respuestas de los participantes con respecto a la percepción que tienen de la habitabilidad del espacio público, se usó la escala multidimensional de coordenadas de orden parcial (POSAC) (por sus siglas del inglés Partial Order Scalogram Análysis) (Shye, 1985, 2009)33.
El análisis se llevó a cabo sobre las respuestas a los 47 ítems de la escala de satisfacción respecto a cada una de las ciudades. Como puede observarse en la figura 4, el grado de satisfacción resulta no converger sobre la diagonal, lo que implica que no existe unicidad en la percepción de satisfacción entre las diferentes ciudades en relación con las condiciones evaluadas.

El análisis de los gráficos secundarios que arroja Posac sobre cada ciudad se presenta en las figuras 5 y 6 , indicando el valor promedio de cada uno de los ítems dentro de la escala de 1 a 7.

A modo de sinopsis, las figuras 5 y 6 evidencian un aspecto común entre todas las ciudades que corresponde a los mayores niveles de satisfacción con los ítems 1 y 35 , que son a la ausencia de

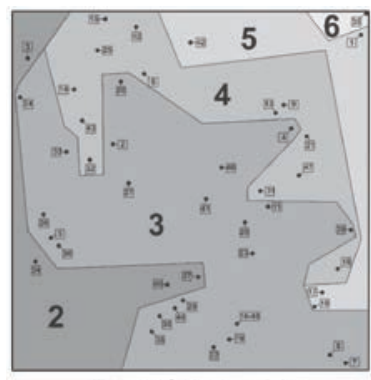

Bogotá-Colombia

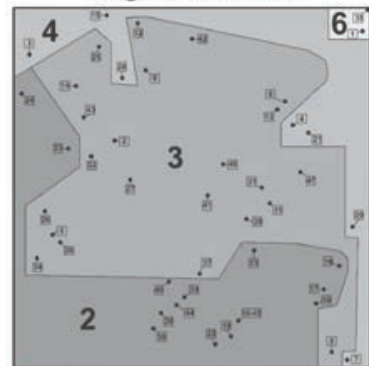

San Cristóbal-Venezuela

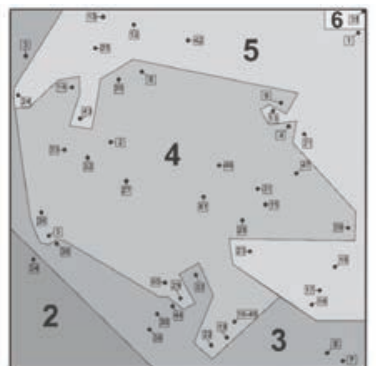

Medellin-Colombia

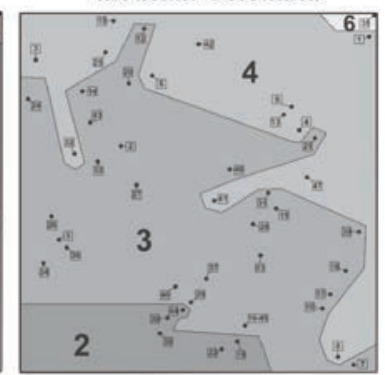

Fortaleza-Brasil

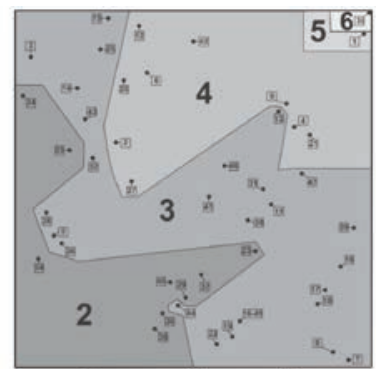

Caracas-Venezuela

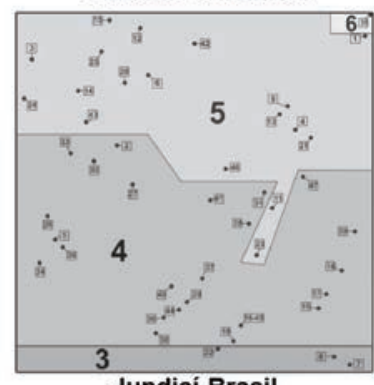

Jundiai-Brasil

Figura 5. Análisis Posac secundario por ciudades: Bogotá, Medellín, Caracas, San Cristóbal, Fortaleza y Jundiaí

El programa toma como referencia el valor promedio de las valoraciones que se asignan a los ítems en relación con variables ordinales o nominales que para, el caso, fue la ciudad de residencia. Posac arroja dos tipos de gráficos: uno principal, en el que se puede observar los ítems a ser analizados resultado de la valoración que hacen los participantes, y unos secundarios que muestran la misma distribución del variable a analizar. En Posac el ítem o afirmación menos gráfico principal indicando los valores promedio que fueron asignados en relación con cada uno de los valores de la valorada se observa en el rincón izquierdo más bajo, mientras que la más valorada se encuentra en el rincón derecho más alto. El gráfico principal se puede analizar en términos cuantitativos si se mira la distribución de las afirmaciones a partir del ángulo superior derecho hasta el ángulo inferior izquierdo, y cualitativos al mirarlo desde el ángulo superior izquierdo hasta el ángulo inferior derecho, lo que refleja el grado de dispersión o variabilidad a que da lugar la variable nominal que se está estudiando, para el caso de la ciudad. 

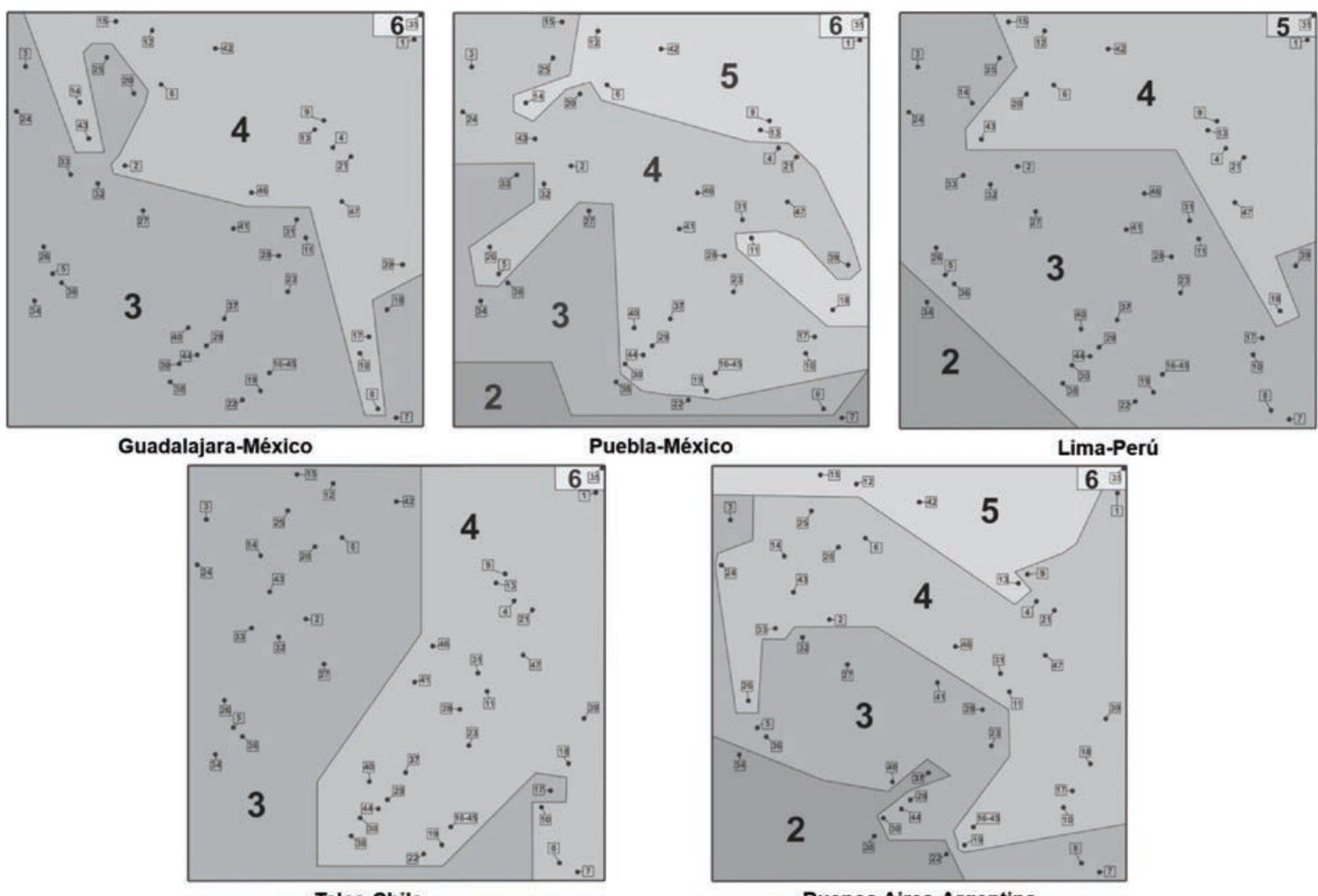

Puebla-México

Lima-Perú

Talca-Chile

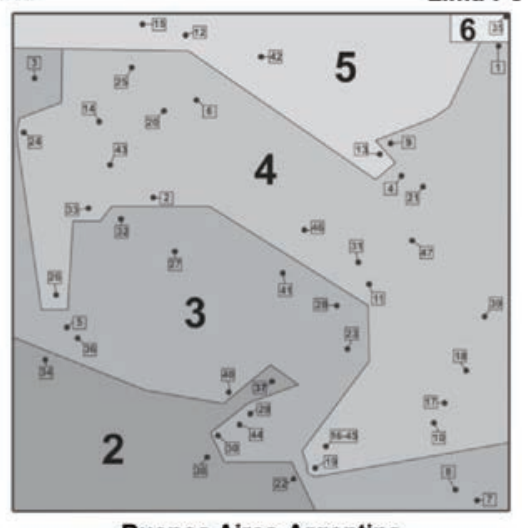

Buenos Aires-Argentina

Figura 6. Análisis Posac secundario por ciudades: Guadalajara, Puebla, Lima, Talca y Buenos Aires

malos olores en el espacio público y el clima predominante en la ciudad, con excepción de Buenos Aires, Argentina. También resulta notorio que los habitantes de Fortaleza, Guadalajara, Jundiaí, Puebla, Lima y Talca presentan satisfacción moderada respecto a la variedad de espacios públicos que ofrece la ciudad y la diversidad de lo que puede observarse o experimentarse. En cuanto a Bogotá, Buenos Aires, Fortaleza, Guadalajara, Medellín y Jundiaí muestran una satisfacción moderada con la existencia de cajeros automáticos y para Talca, Lima, Buenos Aires, Guadalajara y Jundiaí existe gran satisfacción por la realización de actividad cultural gratuita, y con la presencia de manifestaciones religiosas en el espacio público, y por los espacios públicos para practicar deporte (ítem 21). Se identificó poca satisfacción en Talca, Medellín, Lima, Buenos Aires, Caracas y Bogotá por el ruido de las calles. También se observó baja satisfacción de San Cristóbal, Guadalajara, Fortaleza y Buenos Aires respecto al seguimiento de las normas de tránsito. Cabe destacar que las ciudades que ubicaron menos ítems en los grados más bajos de satisfacción ( $\bar{x}=2$ ) fueron Guadalajara, Jundiaí y Talca, ciudades en las que ningún elemento del espacio público alcanzó dichos niveles, en tanto las ciudades de Lima, Medellín y Puebla coincidieron otorgando una baja calificación a la contaminación auditiva (ítem 34) y a la presencia de habitantes de calle (ítem 7). Por el contrario, los habitantes de Caracas y San Cristóbal tendieron a calificar más ítems con un menor grado de satisfacción $(\bar{x}=2)$ en comparación con las demás ciudades. Por ejemplo, los habitantes de ambas ciudades venezolanas expresaron estar insatisfechos en relación con la presencia de elementos de seguridad (ítems 29 y 30), el comercio informal (ítem 33), el 
estado de la malla vial (ítem 40) y el respeto por las normas de tránsito (ítem 38).

La mayoría de los habitantes de las ciudades bajo estudio está satisfecha con el clima y los olores, lo cual es coherente con estar satisfecha con los espacios existentes para hacer deporte, la diversidad en los espacios públicos disponibles y que se reconozca también la variedad del paisaje experiencial para quien los recorre. Ello predispone a un factor que causa aun mayor satisfacción: la programación de actividades culturales gratuitas en dichos espacios.

Por el contrario, hay insatisfacción generalizada con el ruido, la contaminación auditiva, y, relacionado con ello, con el caos vial, el estado de las calles y el poco respeto por las normas de tránsito vigentes en la mayor parte de las ciudades. A esto se agregan las ciudades donde hay mayor insatisfacción con el comercio informal, la suciedad en las calles, la falta de iluminación nocturna, y, relacionado con ello, la inseguridad y la ausencia de infraestructura para la movilidad no motorizada. Dichas ausencias contrastan con las inversiones que se han hecho en estas ciudades, por un lado, en lo que respecta a la movilidad no motorizada, que se ha venido imponiendo en varias de estas ciudades, y, por otro, lo que indica el mejoramiento de los espacios públicos desde la perspectiva de la inversión en infraestructura en cuanto a mobiliario urbano y elementos naturales que facilitan su uso y la apropiación espacial.

Finalmente, el análisis evidenció una marcada diferencia entre varias ciudades respecto al grado de satisfacción que sus habitantes le atribuyen a distintos aspectos del espacio público. Por ejemplo, Bogotá se diferenció de San Cristóbal en cuanto a la infraestructura para movilizarse en bicicleta, elemento que alcanzó un promedio de 3 para Bogotá y de 2 para San Cristóbal. Tal diferencia también se hizo presente al comparar ambas ciudades venezolanas con Jundiaí a propósito del aseo de las calles y la iluminación nocturna, o al comparar esta última con Bogotá en relación con la calidad del aire percibido. Por su parte, los habitantes de Medellín fueron los únicos que manifestaron estar medianamente satisfechos $(\bar{x}=5)$ con el mobiliario en el espacio público, en tanto los habitantes de Jundiaí calificaron favorablemente más aspectos en comparación con las demás ciudades, siendo los únicos que dijeron estar medianamente satisfechos $(\bar{x}=5)$ con las manifestaciones religiosas (ítem 4), los elementos naturales del espacio público (ítem 20) y su potencial para hacer ejercicio (ítem 46). Futuras investigaciones deberán incluir ítems que exploren dimensiones más generales que pudieran, igualmente, estar influyendo en la valoración de la habitabilidad del espacio público, y ser responsables en alguna medida de las diferencias entre ciudades, como aspectos geográficos (topografía y climatología, dos estaciones vs. cuatro estaciones), aspectos sociales coyunturales a la valoración (situaciones sociopolíticas, como la migración) y culturales (religiones y costumbres locales).

\section{Análisis sobre la habitabilidad general}

Respecto a la percepción de habitabilidad general (ítem 48), la figura 7 muestra una comparación de los promedios obtenidos de la calificación de la habitabilidad general en las ciudades en forma descendente, siendo Jundiaí la mejor evaluada y Caracas la peor.

Al cruzar la información de las dos escalas, satisfacción e importancia, para el conjunto de las 11 ciudades latinoamericanas (figura 8), se observa que la mayor concentración de los ítems se encuentra en el cuadrante superior izquierdo, correspondiente a lo que se evalúa como muy importante pero que a la vez es evaluado con menos satisfacción. Dentro de este conjunto de ítems se encuentran principalmente aquellos que corresponden a la dimensión de estructura y dinámicas urbanas: el mobiliario, el medio ambiente, la movilidad, la seguridad y la actividad comercial. Estos resultados coinciden con los aportados por Vivas (2006), para quien las ciudades latinoamericanas 


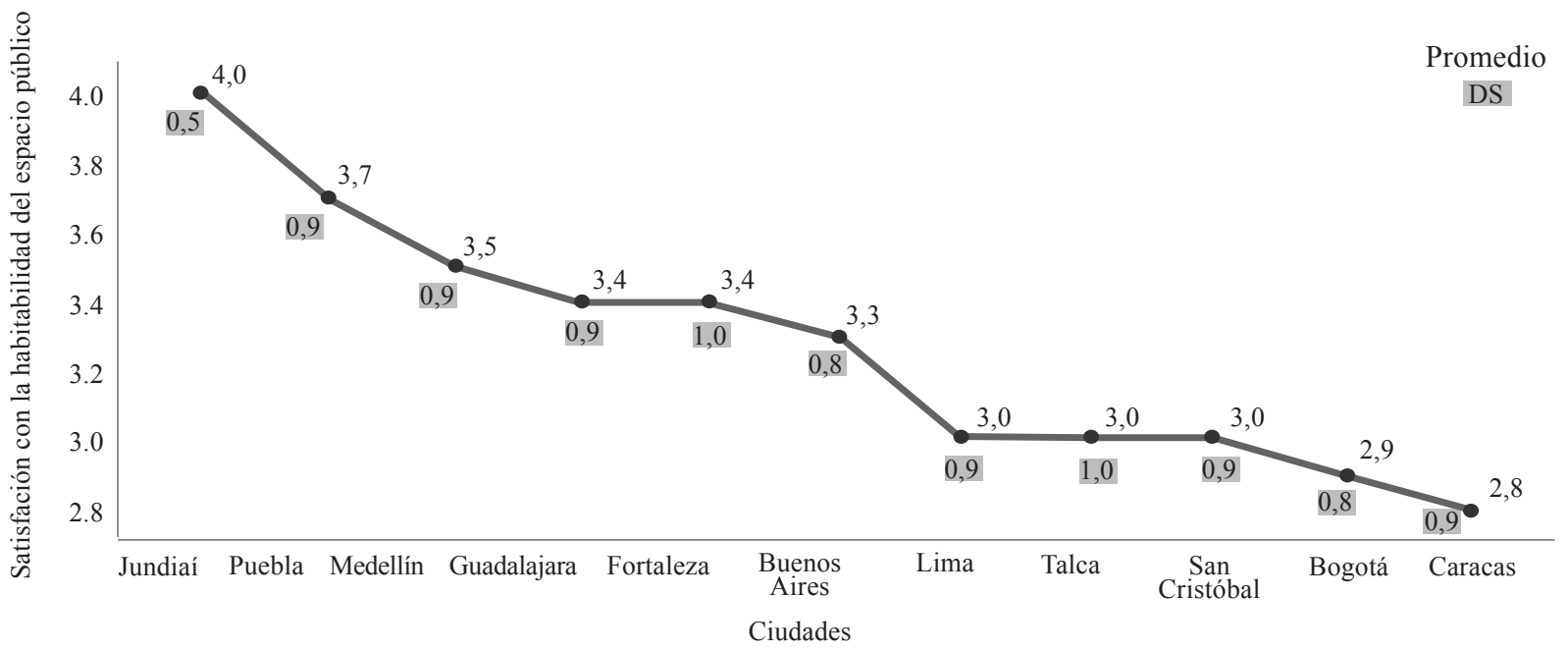

Figura 7. Promedio de la valoración de la habitabilidad entre ciudades a partir de la satisfacción general

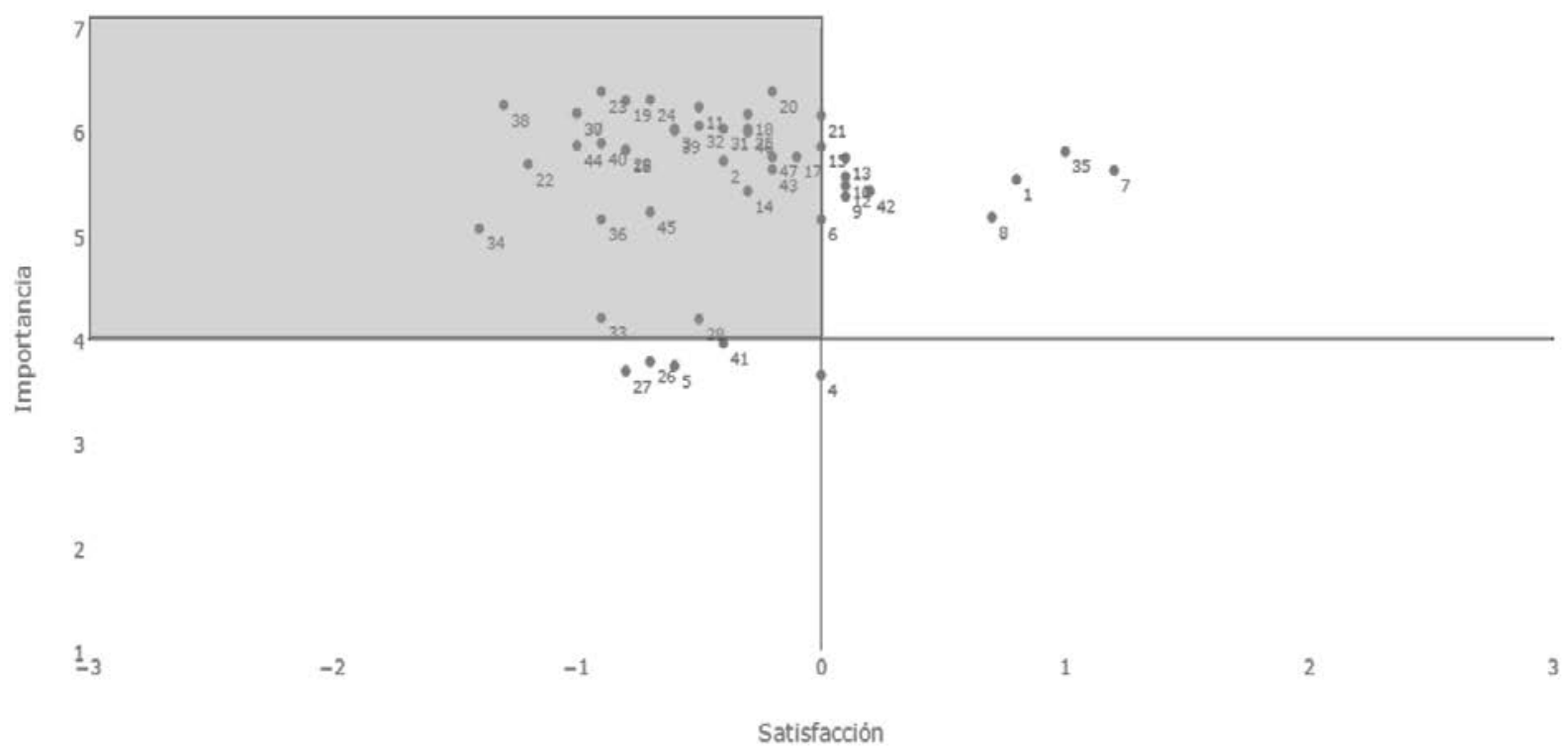

Figura 8. Importancia y satisfacción de la habitabilidad entre ciudades

ofrecen poco atractivo justamente por carecer de los anteriores indicadores que dificultan la interacción social y la identificación, uno de los aspectos más importantes para evaluar el bienestar y la calidad de vida, según la perspectiva de Blanco y Díaz (2005). Se puede afirmar a partir de la figura 8 que los ciudadanos no son indiferentes con el espacio público de sus ciudades.

\section{Conclusiones}

Los resultados permitieron identificar algunas dimensiones clave mediante las cuales las personas hacen la valoración del espacio público, que incluyen: las expresiones artísticas, la calidad del aire, las distintas dinámicas culturales, las características de estructura físico-espacial y la 
dinámica urbana, el seguimiento de reglas para la convivencia, las manifestaciones públicas, la preocupación por la atención de las necesidades de las personas en vulnerabilidad social que hacen presencia en el espacio público, y el aprovechamiento económico. Dichas dimensiones reflejan en buena medida la estructura conceptual mediante la cual los habitantes urbanos hacen la valoración del espacio público, que se refiere principalmente a la función que piensan debe cumplir este para que sea habitable y, en consecuencia, contribuya a mejorar la calidad de vida de las personas en la ciudad.

Igualmente, la investigación permitió observar la importancia que le dan las personas a los aspectos que tienen que ver con la estructura físico-espacial, su diseño y la calidad del ambiente, restándole importancia a algunas expresiones culturales, por lo que consideramos que, de parte de los administradores de la ciudad, se debería gestionar una mayor oferta de diversas actividades de este tipo en distintos sectores de la ciudad, de tal manera que se pueda ampliar la cobertura a más personas. Pensamos que la pobre valoración que se ha hecho de dichas actividades en este estudio obedece a que pocas personas tienen acceso a participar de ellas y a que las que se ofrecen no satisfacen las necesidades de distintos sectores de la población.

$\mathrm{Al}$ analizarse estos hallazgos desde una perspectiva educativa, la importancia atribuida a ciertas condiciones del espacio público no puede desligarse de los procesos de formación que las personas han recibido no solo en la escuela, sino en su familia. La valoración se hace como un reflejo de la manera como han sido formadas $y$, en consecuencia, lo que demandan de un espacio público. Por ello, desde un planteamiento de política pública deberán incorporarse a los programas de educación ciudadana o urbanidad la enseñanza de las reglas que deben guiar el comportamiento de las personas en relación con el cuidado del ambiente urbano y la promoción de la participación de los ciudadanos en su protección. En una dirección similar, se puede afirmar que la concepción que se tiene de los espacios públicos en Latinoamérica remite al análisis de las similitudes en la norma que regula estos espacios, la cual se refleja en los códigos de policía de las ciudades estudiadas (Páramo \& Burbano, 2018).

Sin embargo, se evidencian diferencias entre las distintas ciudades: los habitantes de Jundiaí, Puebla y Medellín se encuentran más satisfechos con el espacio público de sus ciudades que los de Bogotá y Caracas. Al respecto, será importante desarrollar una investigación que establezca los grados de correlación entre los niveles de satisfacción identificados en este estudio, como medición subjetiva, con indicadores objetivos como la calidad del aire, las tasas de criminalidad y la densidad poblacional, entre otro tipo de indicadores objetivos, e incorporar nuevas variables que contextualicen las características individuales de cada ciudad, como fue señalado.

Resulta preocupante observar los muy bajos niveles de satisfacción que tienen, en la mayoría de las ciudades, los ciudadanos latinoamericanos encuestados con los componentes de sus espacios públicos, lo que significa claramente que estos espacios no están cubriendo necesidades básicas del ser humano, desde la propuesta de Max-Neff et al. (1986). Estos espacios, que son el entorno de las viviendas, no están realmente adicionando habitabilidad sino restando; el efecto de no satisfacer puede también revertirse en llevar al ciudadano a sentir parcialmente insatisfacción con su vivienda (i.e. por las características de su ubicación), si lo analizamos bajo las propuestas de Mercado et al. (1995) y Landázuri y Mercado (2004).

Los resultados del estudio contribuyen al cuerpo de conocimiento de la psicología social y ambiental, el urbanismo y la planeación urbana en la medida en que se introduce la habitabilidad del espacio público como un indicador subjetivo, importante para la evaluación de la calidad de vida urbana, la cual debe sumarse a los indicadores objetivos ya existentes. La difusión de los hallazgos 
sobre la habitabilidad del espacio público de las ciudades mediante instrumentos, como el utilizado en este estudio, puede contribuir a la planeación y la promoción de la participación ciudadana para el mejoramiento de la calidad de vida urbana, en la medida en que hace visible la problemática identificada por los ciudadanos y da elementos a la comunidad para demandar la atención de sus necesidades en la ciudad. Las instituciones responsables de la gestión del espacio público en las ciudades latinoamericanas deberían incorporar estas dimensiones en el desarrollo de políticas y adelantar acciones para considerar el espacio público objeto de planificación, lo cual no se da por igual en las ciudades latinoamericanas.

Finalmente, surgen a partir del estudio algunos interrogantes que deberán resolverse en investigaciones futuras: ¿qué otras dimensiones son importantes de identificar en la habitabilidad del espacio público? ¿Qué tipo de políticas públicas se pueden diseñar para mejorar las condiciones del espacio público de las ciudades latinoamericanas? ¿Qué otras dimensiones son importantes de identificar en la habitabilidad del espacio público? ¿Qué papel juegan algunas dimensiones psicológicas, como la identidad, el apego y la apropiación, en la valoración que se hace del espacio público?

\section{Agradecimientos}

Se agradece la participación de nuestras colegas Zulmira Bomfim de la Universidad Federal de Ceará por su participación en la recolección de información de Jundiaí, Brasil; Patricia Ortega de la UnAM, por los datos de Puebla, México; Angela Coelho Moniz de la Sociedade Padre Anchieta de Ensino S/C Ltda., por la recolección de información de Fortaleza, Brasil; y Rosario Zapata, por los datos recogidos de Lima, Perú.

\section{Referencias}

Alcalá, L. (2007). Dimensiones urbanas del problema habitacional. El caso de la ciudad de Resistencia, Argentina. Boletín del Instituto de la Vivienda INVI, 22(59), 35-68.

Ardila, R. (2003). Calidad de vida: una visión integradora. Revista Latinoamericana de Psicología, 35(2), 161-164.

Blanco, A. \& Díaz, D. (2005). El bienestar social: su concepto y medición. Psicothema, 17, 582-589.

Borg, I. \& Groenen, P. J. F. (2005). Modern multidimensional scaling ( $2^{\mathrm{a}}$ ed.). Nueva York: Springer.

Borja, J. \& Muxi, Z. (2000). El espacio público, ciudad y ciudadanía. Barcelona: Electa.

Bronfenbrenner, U. (1971). La ecología del desarrollo humano. Barcelona: Paidós.

Burbano, A. (2014). La investigación sobre el espacio público en Colombia: su importancia para la gestión urbana. Territorios, (31), 185-205. DOI: dx.doi.org/10.12804/territ31.2014.08

Carrión, F. (2004). Espacio público: punto de partida para la alteridad. En F. Velásquez (comp.), Ciudad e inclusión: por el derecho a la ciudad (pp. 55-79). Santiago de Chile: SUR.

Data Team (2015). The world's most "liveable" cities. The Economist. Recuperado de http://www. economist.com/blogs/graphicdetail/2015/08/ daily-chart-5

Delgado, M. (2011). El espacio público como ideología. Madrid: Los libros de la Catarata.

Gabinete de Comunicación Estratégica (2013). Las ciudades más habitables de México. Recuperado de http://www.gabinete.mx/descargas/encuesta_nacional/DOSSIER2013/DOSSIER_GCE_ CIUDADES.pdf

García, I. (2014). La globalización y los espacios públicos. En E. Licona (comp.), Espacio y espacio público (pp. 39-77). Puebla: Benemérita Universidad Autónoma de Puebla.

García-Canclini, N. (2005). La antropología urbana en México. México D.F.: Fondo de Cultura Económica. 
Jiménez-Domínguez, B. (2007). Urban appropriation and loose spaces in the Guadalajara cityscape. En K. A. Franck \& Q. Stevens (eds.), Loose space (pp. 96-112). Nueva York: Routledge.

Landázuri, A. \& Mercado, S. (2004). Algunos factores físicos y psicológicos relacionados con la habitabilidad interna de la vivienda. Medio Ambiente y Comportamiento Humano, 5(1-2), 89-113.

Leva, G. (2005). Indicadores de calidad de vida urbana. Teoría y metodología. Buenos Aires: Universidad Nacional de Quilmes.

Licona, E. (2007). El zócalo de la ciudad de Puebla. Actores y apropiación social del espacio. México D.F.: BUAP.

Marquina, D. \& Pasquali, C. (2006). Impacto del entorno en los niveles de satisfacción proporcionados por viviendas de interés social. Perfiles, 26, 25-40.

Max-Neff, M., Elizalde, A. \& Hopenhayn, M. (1986). Desarrollo a escala humana. Santiago de Chile: Cepaur.

Mercer (2015). Vienna tops latest quality of living rankings. Londres: Mercer. Recuperado de http://www.uk.mercer.com/newsroom/2015-quality-of-living-survey.html

Mercado, S. (1995). Habitabilidad de la vivienda urbana. México D. F.: UNAM.

Mercado, S., Ortega, P., Estrada, C. \& Luna, M. (1995). Habitabilidad de la vivienda urbana. México: UNAM.

Monocle's quality of life survey is an alternative top destinations for 2015 (2015). Skift: Destinations. Recuperado de http://skift.com/2015/06/12/ monocles-quality-of-life-survey-is-an-alternative-places-to-go-for-2015/

Moreno, S. (2008). La habitabilidad urbana como condición de calidad de vida. Palapa, III(2), 47-54.

Moyano, E., Núñez, D, \& Jiménez, A. (2010). Calidad de vida y psicología. En E. Moyano (comp.),
Calidad de vida y psicología (pp. 29-94). Talca: Universidad de Talca.

Oldemburg, R. (2011). Prólogo. En P. Páramo (aut.), Sociolugares (pp. 7-9). Bogotá: Universidad Piloto de Colombia.

Páramo, P. (2007). El significado de los lugares públicos para la gente de Bogotá. Bogotá: Fondo Editorial Universidad Pedagógica Nacional.

Páramo, P. \& Burbano, A. (2013). Valoración de las condiciones que hacen habitable el espacio público en Colombia. Territorios, 28, 187-206.

Páramo, P. \& Burbano, A. (2018). Convivencia ciudadana en ciudades latinoamericanas. Bogotá: Universidad Pedagógica Nacional.

Red Colombiana de Ciudades Cómo Vamos (2014). Red de Ciudades cómo Vamos. Recuperado de http://redcomovamos.org/

Shye, S. (1985). Multiple scaling: the theory and application of Partial Order Scalogram Analysis. Amsterdam: North-Holland.

Shye, S. (2009). Partial order scalogram analysis by coordinates (Posac) as a facet theory measurement procedure: how to do Posac in four siple steps. Recuperado de https://www.researchgate. net/publication/263932933

Silva, A. (1992). Imaginarios urbanos. Bogotá y Sao Paulo: cultura y comunicación urbana en América Latina. Bogotá: Tercer Mundo Editores.

Valladares, R., Chávez, M. \& López, M. (2015). Elementos de la habitabilidad urbana. En R. Valladares (coord.), Diversas visiones de la habitabilidad (pp. 15-39). Puebla: RNIU.

Vergara, A. (2003). Identidades, imaginarios y simbolos del espacio urbano, Quebec, La Capitale. México D.F.: Internationale des Etudes Québecoises.

Vivas, F. (2006). Patología del espacio público: las calles del barrio obrero en San Cristóbal, Venezuela. Quivera, 8(2), 130-150.
Recibido: mayo 17, 2016 Aprobado: octubre 10, 2017 